\title{
Editorial Report 2015
}

\author{
Jan van Ours 1
}

Published online: 12 February 2016

(C) Springer Science+Business Media New York 2016

The 4 issues of De Economist published in 2015 contain 19 papers of which 15 papers were published in regular issues and 4 papers were published in a special issue with guest editor Bas ter Weel on unemployment in the Great Recession and beyond.

The evolution of the impact factor of De Economist is presented in the Fig. 1. As shown, after fluctuating from 0.1 to 0.3 in the period 2001-2008, the impact factor increased to 1.02 in 2013 to drop to 0.58 in 2014 . The Article Influence Score shows a similar development with a peak of 0.57 in 2013 and a value of 0.45 in 2014 .

Table 1 provides information about the editorial process. In 2015 there were 60 regular submissions which is a substantial increase as compared to earlier years. However, of these submissions so far only 9 were accepted, 43 were rejected, and 8 are still in the editorial process. Of the rejected papers 35 were desk-rejections, i.e. rejected within a week after submission. Excluding the papers which were desk-rejected there were 25 regular submissions which is about the same as earlier years. Of the papers excluding desk rejections the acceptance rate in 2014 was $45 \%$. In 2015 this was 36\%, but there are still 8 papers in the editorial process so the 2015 acceptance rate might go up in the course of 2016.

Finally, the table shows the relationship between year of submission and year of publication. For example, of the 15 papers submitted and accepted for publication in 2015, 9 were published in 2015 while the remaining 6 will be published in 2015 .

Since 2011 the editors allow authors to include in the submission editorial letters and referee reports from failed submissions at other journals. This does not mean that no other referees will be used, but the use of previous information will speed of our editorial process.

\footnotetext{
$凶 \quad$ Jan van Ours

deeconomist@gmail.com

1 Tilburg, The Netherlands
} 


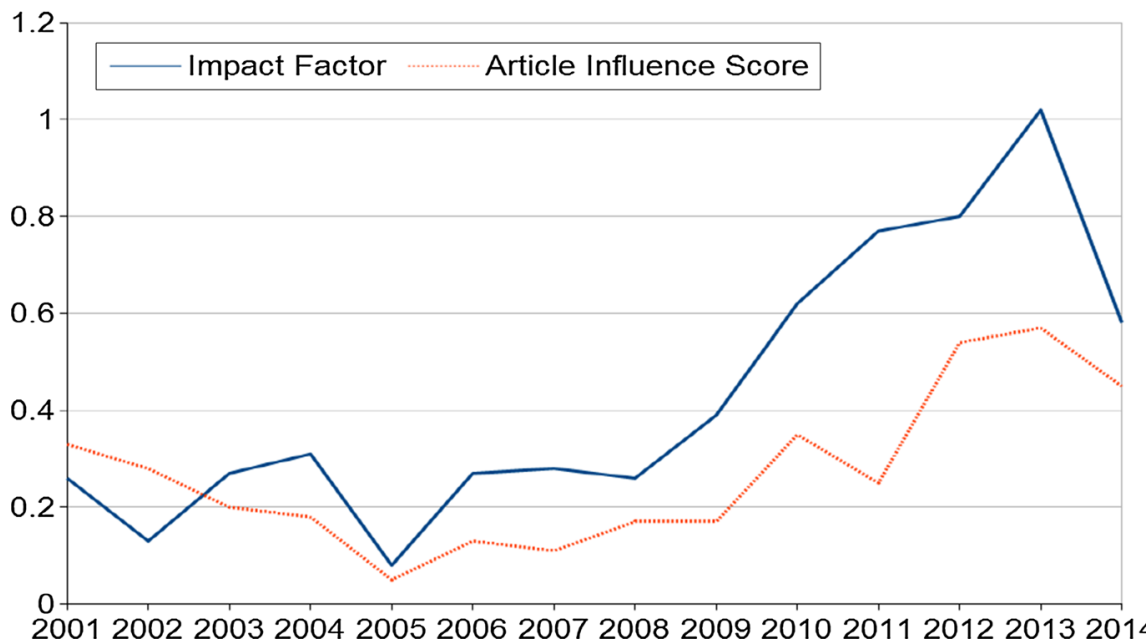

Fig. 1 Evolution of impact factor and Article Influence Score; 2001-2014

Table 1 Results of the editorial process

\begin{tabular}{llllll}
\hline Number of papers submitted in & 2015 & 2014 & 2013 & 2012 & 2011 \\
\hline Accepted & 9 & 10 & 12 & 10 & 8 \\
Regular rejection & 8 & 12 & 12 & 19 & 18 \\
Desk rejection & 35 & 25 & 25 & 15 & 17 \\
Stock December 31, 2015 & 8 & 0 & 0 & 0 & 0 \\
Sub-total regular submissions & 60 & 47 & 49 & 44 & 43 \\
Special issues + editors contributions & 6 & 8 & 10 & 4 & 9 \\
Total & 66 & 55 & 59 & 48 & 52 \\
Regular papers excl. desk rejections & & & & & \\
Number & 25 & 22 & 24 & 29 & 26 \\
Acceptance rates (\%) & 36 & 45 & 50 & 34 & 31 \\
Still undecided (\%) & 32 & - & - & - & - \\
Accepted papers & 15 & 18 & 22 & 14 & 17 \\
Published in & & & & & \\
2016 & 6 & - & - & - & - \\
2015 & 9 & 8 & 2 & - & - \\
2014 & - & 10 & 9 & 1 & - \\
2013 & - & - & 11 & 8 & 1 \\
2012 & - & - & - & 5 & 14 \\
2011 & - & - & - & - & 2 \\
\hline
\end{tabular}


The editorial board welcomes Bas ter Weel as new editor as of the 1st of January 2016. The editors of De Economist would like to thank the following reviewers for their contribution to the editorial process in 2015 :

\begin{tabular}{lll}
\hline Yvonne Adema & Jan Jacobs & Jan Potters \\
Bernard van den Berg & Eelke de Jong & Ward Romp \\
Michiel Bijlsma & Adriaan Kalwij & Bert Scholtens \\
Hans Bloemen & Pierre Koning & Bert Schoonbeek \\
Lans Bovenberg & Peter Kooreman & Arthur van Soest \\
Rob Euwals & Boris van Leeuwen & Adriaan Soetevent \\
Didier Fouarge & Jochen Mierau & Bas Straathof \\
Philip Hans Franses & Asako Ohinata & Vincent Vandenberghe \\
Joop Hartog & Franz Palm & Jeroen van de Ven \\
Marco Hoeberichts & Thomas Post & Aico van Vuuren \\
\hline
\end{tabular}

